\title{
THE ILIAC APOPHYSIS AND THE EVOLUTION OF CURVES IN SCOLIOSIS
}

\author{
Alexander L. Zaoussis, Athens, Greece, and J. I. P. James, Edinburgh, Scotland
}

From the Institute of Orthopaedics and the Royal National Orthopaedic Hospital, London and Stanmore

In 1948 Risser reported an observation made at the Los Angeles Orthopaedic Hospital that " the completion of ossification excursion of the iliac apophysis has been proven to occur simultaneously with the completion of vertebral growth, and with it the curvature is static ...". Although this was confirmed by other authors (Steindler 1950, James 1954, Donaldson 1957) no statistical evidence has yet been offered to support the observation, nor have data been presented on the relationship between the excursion of this ossification centre and the evolution of scoliotic curves.

For the surgeon engaged in the management of scoliosis and seeking for a sign that would be decisive for or against operative intervention, the observation made by Risser is of great practical importance.

The aim of this investigation has been to study the radiological characteristics of this ossification centre, its relation to other signs of maturation such as the onset of menstruation and the growth of the apophyses of the vertebral bodies, and its relationship with the progression of the curve in scoliosis.

More than 800 patients with mature curves seen at the Royal National Orthopaedic Hospital in the last ten years were reviewed, and of these, 224 were found suitable for this investigation. In each there was at least one radiograph of the curve available at the time the iliac apophyses had completed their excursion (that is, reached the posterior limit of the iliac crest), and one follow-up film taken not less than a year later.

\section{CURVE PROGRESSION AND THE ILIAC APOPHYSIS}

In approximately half of the 224 cases a series of radiographs from the first appearance of the iliac apophyses until after their fusion to the crests was available. Observations on the evolution of curves have been grouped into three: there are the changes in the curve occurring

TABLE I

The Maximum and Average Amount of Increase in the Curvature Observed During the Three Periods

\begin{tabular}{|c|c|c|c|c|}
\hline \multicolumn{3}{|c|}{ Periods } & Maximum increase & Average increase \\
\hline 1 & Between appearance and completion of the apophyses & . & 38 degrees & 13 degrees \\
\hline 2 & After completion of their excursion until fusion & . & 26 degrees & 9 degrees \\
\hline 3 & After fusion of the apophyses to the crest & . & $\begin{array}{c}18 \text { degrees } \\
\text { (only } 1 \text { case } \\
\text { over } 15 \text { degrees) }\end{array}$ & 8 degrees \\
\hline
\end{tabular}

between the appearance of the iliac apophyses and the completion of their excursion, the changes after completion until fusion, and the changes after fusion of the apophyses to the iliac crest. 
An overall picture of the evolution of curves during the three periods is presented in Figure 1. The term "increased" has been used whenever there was an increase in the angle of curve of more than 5 degrees; "unchanged" curves include cases in which the increase was less than 5 degrees or in which an apparent decrease of a few degrees was observed, a variation often due to measuring errors. In each group the percentage of the total cases in which a deterioration of over 15 degrees had occurred is separately indicated. These figures provide

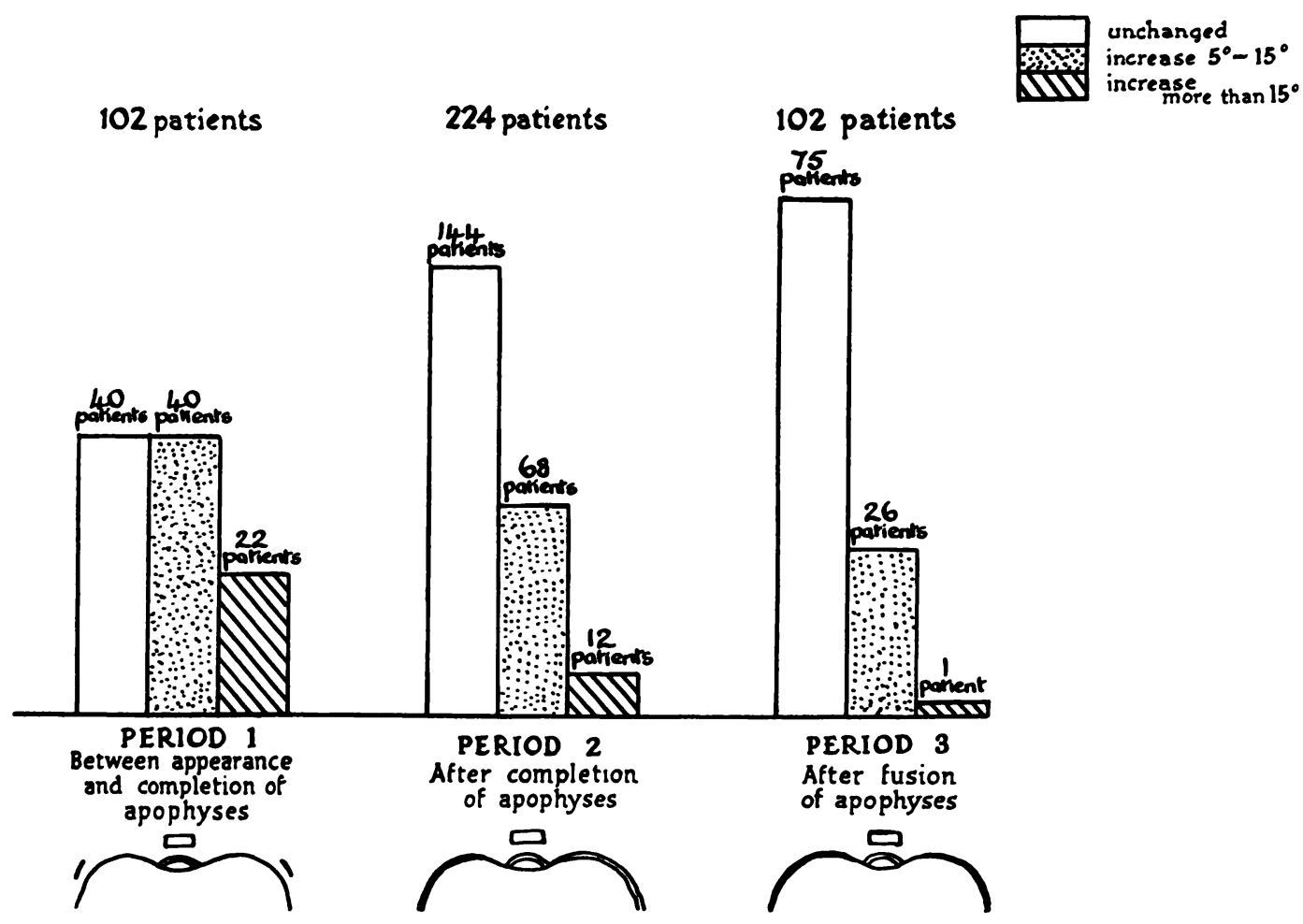

FIG. 1

The evolution of curves during the three periods of growth of the iliac apophyses.

statistical support for the belief that skeletal maturation as indicated by the completion of the iliac apophysis marks the end of significant deterioration in scoliosis.

As can be seen from Table I, even during the first period, before the apophyses had completed their excursion, the increase of the curve was not alarming, averaging 13 degrees. In the two subsequent periods it was naturally less. One should, however, refrain from too much optimism; the increase in each individual period is small, but the total amount of deterioration at the end of the three periods may be significant.

When these cases were analysed from an etiological standpoint it was found that, contrary to the belief of some surgeons, the paralytic curves usually follow the general rule that no significant deterioration occurs after the iliac apophyses have completed their excursion. This is illustrated in Figure 2. Almost half of the cases of paralytic scoliosis were followed long enough (until after fusion of the apophyses to the iliac crest) to demonstrate that deterioration in these curves did not occur at a later stage.

Curves of other etiology than idiopathic and paralytic are not shown in this figure because each group was too small to allow conclusions to be drawn.

\section{THE PRIMARY SITE OF SCOLIOSIS AND THE ILIAC APOPHYSIS}

The evolution of curves during the three periods was studied from the point of view of curve pattern. The worst deteriorations during both the period before and after maturation 
occurred in the combined (double primary) curves regardless of etiology or of age of onset. In a number of cases, however, only one of the two primary curves had deteriorated whereas the other remained unchanged. During the first period, before completion of the iliac apophyses, the combined curves not only showed the highest percentage of deterioration over 15 degrees,

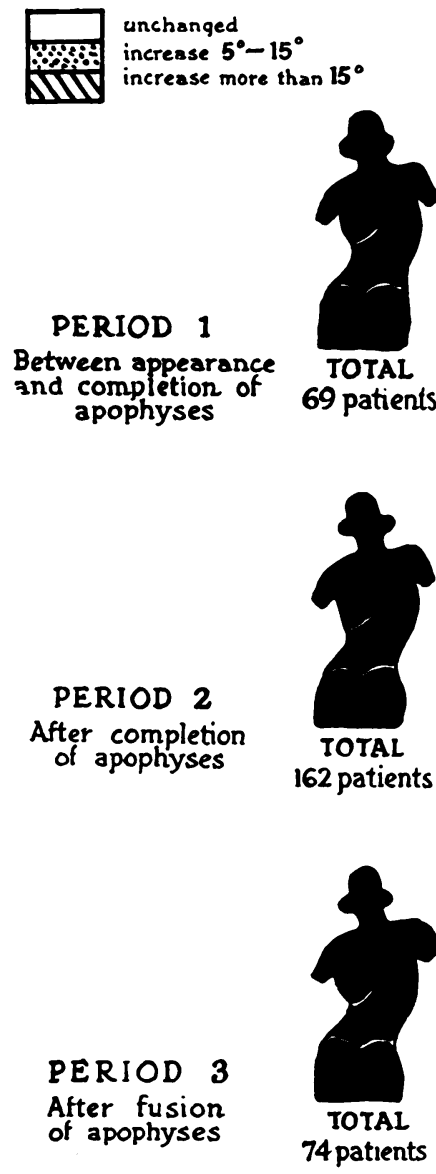

IDIOPATHIC
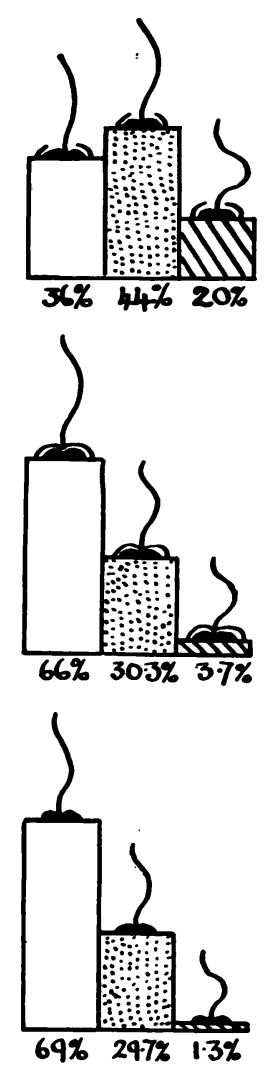

FIG. 2
PARALYTIC
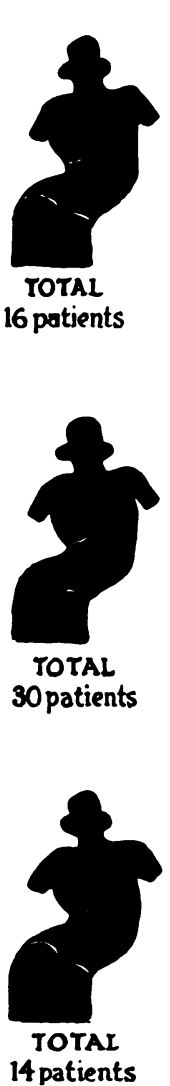
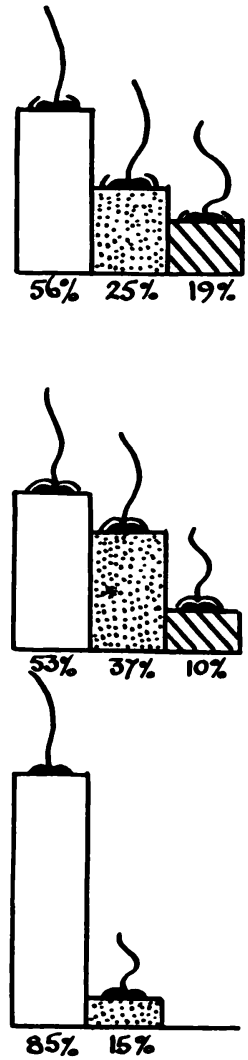

The similarity of curve evolution in idiopathic and paralytic scoliosis in the three growth periods.

but also the most severe deterioration in individual cases. During the second period the thoraco-lumbar curves also showed a high percentage of deterioration over 15 degrees. Figure 3 summarises the distribution of deterioration over 15 degrees according to the pattern of curve during the periods before and after maturation.

\section{THE OSSIFICATION CENTRE OF THE ILIAC CREST}

As expected, considerable variation was found in the time of appearance, completion and fusion of the iliac apophyses. In Table II the rather incomplete data collected from the literature are recorded, together with our own observations.

The radiographs showing the apophyses of all our patients who had paralytic curves were examined separately. It was found that in these patients, too, the apophyses appeared, matured and fused at the times shown in Table II. Only in the female poliomyelitic patients did the apophyses appear and mature a few months later than the average times. 
Risser's (1948) observation that a year usually elapses between appearance and completion of the iliac apophysis was confirmed. Our average figures (for boys and girls, Table II) were slightly longer than his.

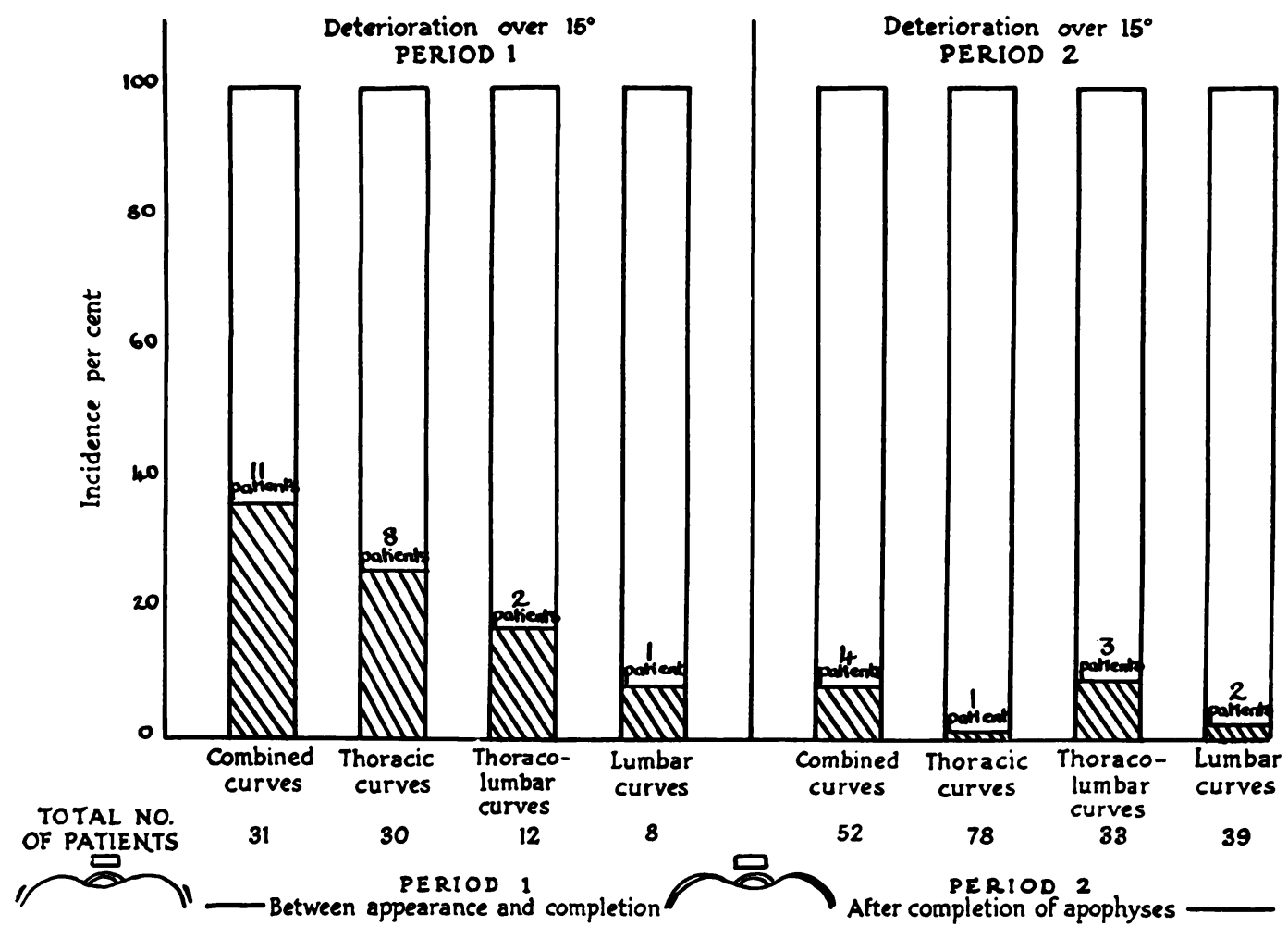

Fig. 3

The incidence of deterioration over 15 degrees in periods 1 and 2 . In period 3 there was only one such case among 102 patients.

In our series the longest period that elapsed between appearance and completion of an apophysis was three and a half years for both boys and girls. The shortest was seven months for both sexes. The apophysis fused to the iliac crests within an average interval of two years after the completion of its excursion in girls, and a little more quickly in boys. The most

TABLE II

The Time of Appearance, Completion and Fusion of the Iliac Apophyses

\begin{tabular}{|c|c|c|c|c|c|c|c|c|c|}
\hline \multirow{2}{*}{\multicolumn{3}{|c|}{ Author }} & \multirow{2}{*}{$\begin{array}{l}\text { Average and } \\
\text { extremes }\end{array}$} & \multicolumn{2}{|c|}{$\begin{array}{c}\text { Age of appearance } \\
\text { (years) }\end{array}$} & \multicolumn{2}{|c|}{$\begin{array}{l}\text { Age of completion } \\
\text { of excursion (years) }\end{array}$} & \multicolumn{2}{|c|}{$\begin{array}{l}\text { Age of fusion } \\
\text { to the crest (years) }\end{array}$} \\
\hline & & & & Boys & Girls & Boys & Girls & Boys & Girls \\
\hline \multicolumn{3}{|c|}{ Waldeyer (quoted by Schinz) } & & $15-16$ & $15-16$ & - & - & $24-25$ & $24-25$ \\
\hline Flecker & . & . & $\begin{array}{l}\text { Average } \\
\text { Earliest }\end{array}$ & $\begin{array}{l}16 \\
13 \frac{1}{2}\end{array}$ & $\begin{array}{l}14 \\
12\end{array}$ & - & - & 21 & 21 \\
\hline Köhler & . & . & & $12-15$ & $12-15$ & - & - & $21-25$ & $21-25$ \\
\hline Zaoussis & and James & . & $\begin{array}{l}\text { Average } \\
\text { Earliest : } \\
\text { Latest }\end{array}$ & $\begin{array}{l}15+ \\
12 \frac{3}{4} \\
17 \frac{1}{2}\end{array}$ & $\begin{array}{l}144 \\
11 \\
18\end{array}$ & $\begin{array}{l}16 \frac{1}{2} \\
13 \\
19 \frac{3}{4}\end{array}$ & $\begin{array}{l}15 \frac{1}{2} \\
12 \frac{1}{4} \\
19 \frac{3}{4}\end{array}$ & $\begin{array}{l}184 \\
15 \frac{3}{4} \\
21 \frac{3}{4}\end{array}$ & $\begin{array}{l}17 \frac{1}{2} \\
13 \frac{1}{2} \\
23 \frac{1}{2}\end{array}$ \\
\hline
\end{tabular}


rapid fusion of an apophysis to the crest was observed in a boy five months after the apophysis had reached the posterior limit; the shortest period observed in girls was six months. The longest time an apophysis took to fuse in this series was six years in a girl, whereas the longest for boys was two and three-quarter years.

Again there was no difference noted when the rate of growth of the apophysis in patients suffering from poliomyelitis was investigated.

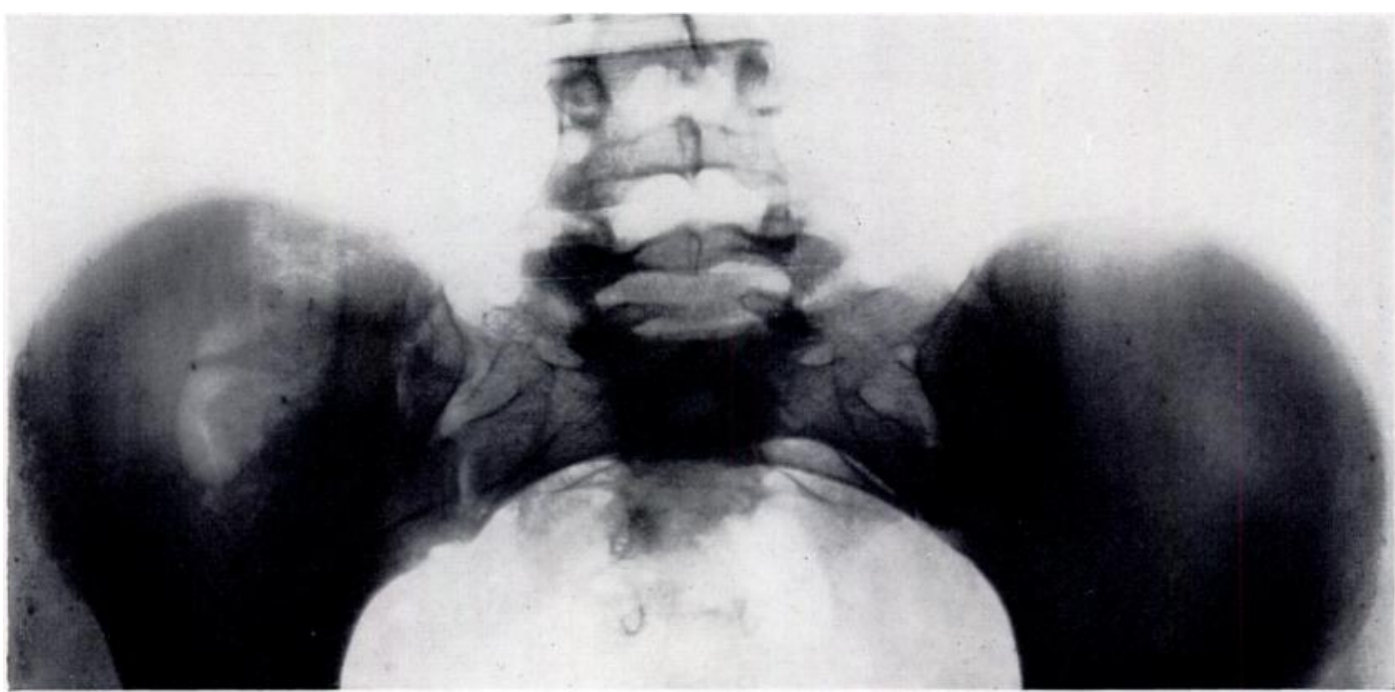

Fig. 4

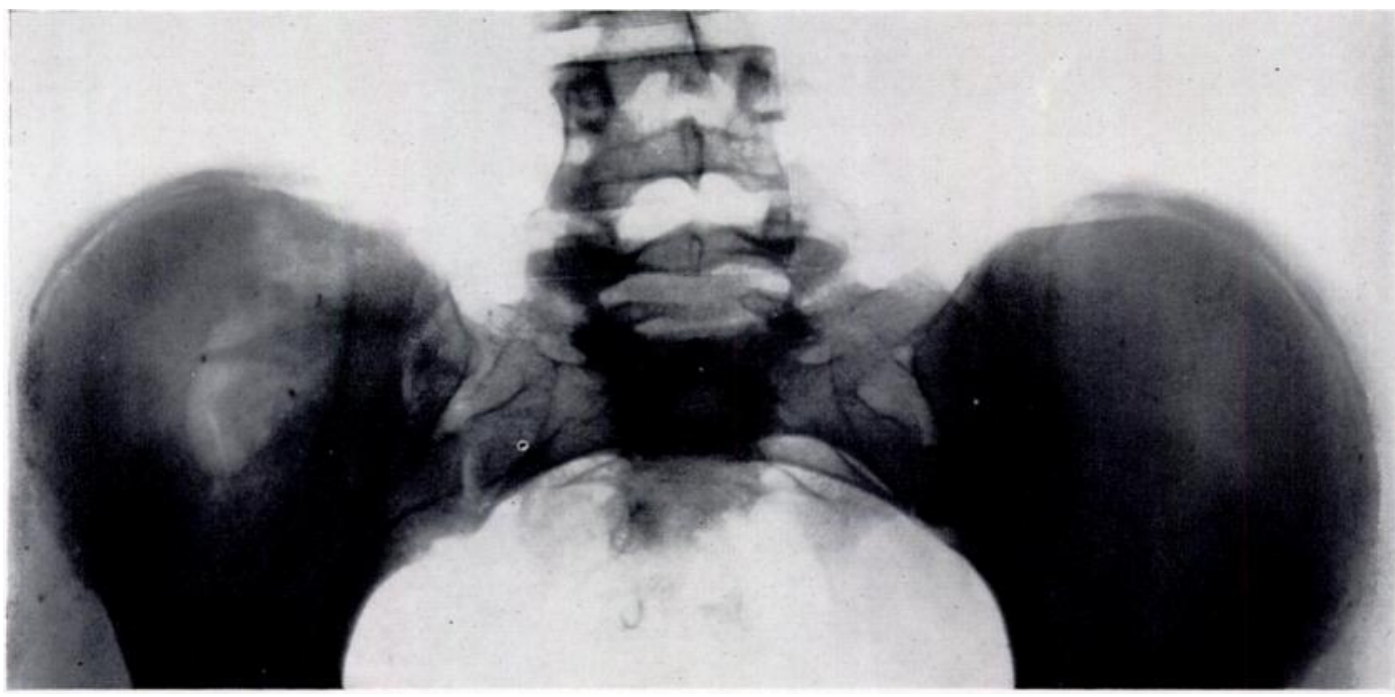

Fig. 5

Figure 4-A view of the iliac apophyses using an ordinary viewing box. Figure 5-The same radiograph in a bright light. The "absent " apophyses have almost completed their excursion.

\section{DEVELOPMENT OF THE ILIAC APOPHYSES}

For the precise assessment of the state of the apophysis the radiograph must be examined in a bright light (Figs. 4 and 5).

In most cases the apophysis makes its appearance at the anterior part of the iliac crest. It then grows backwards along and parallel to the iliac crest (Figs. 6 to 8). Although anatomically 


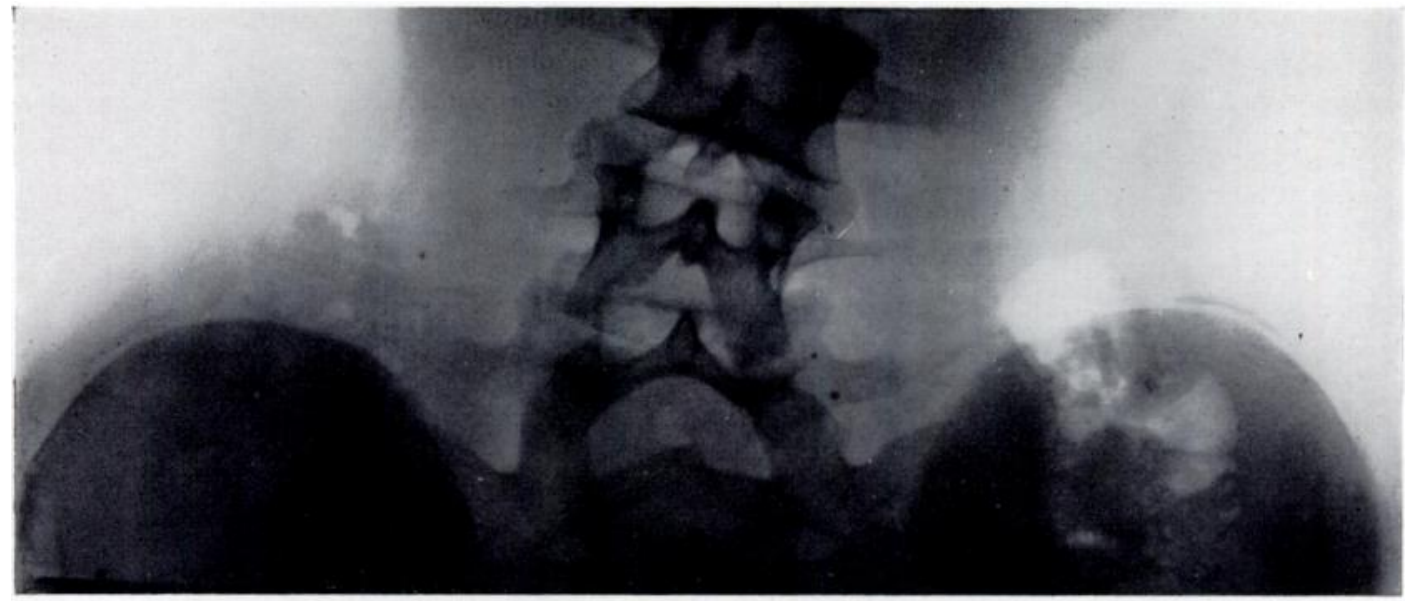

Fig. 6

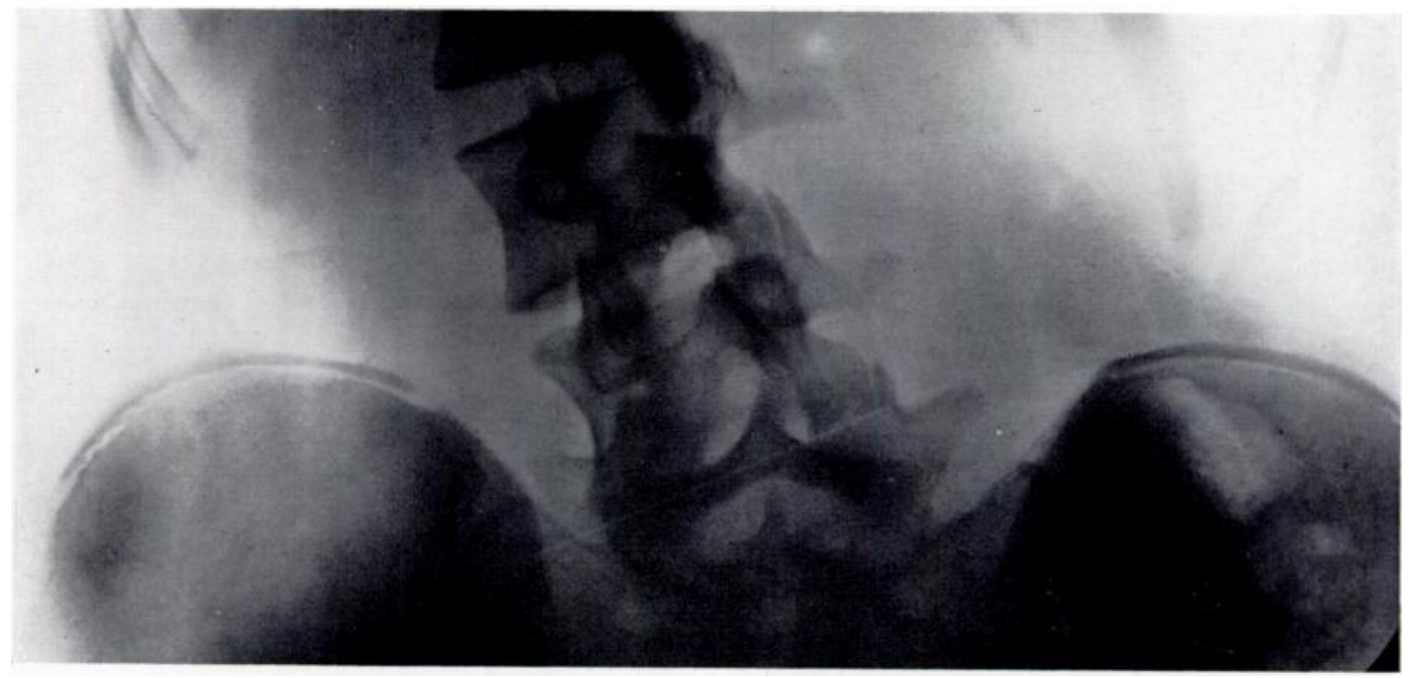

FIG. 7

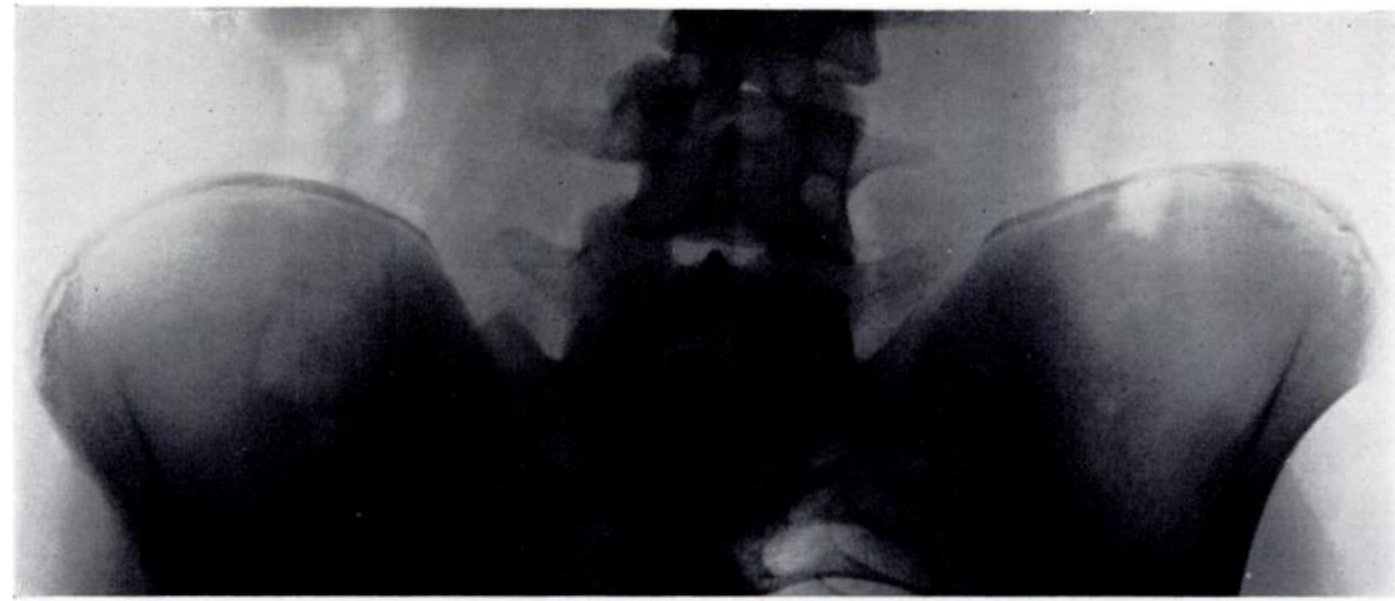

Fig. 8

Figure 6-The apophyses are just visible. Figure 7-The apophysis has "dipped down" on one side. Figure 8-The apophyses are fusing.

vol. 40 B, NO. 3, AUGUST 1958 
the apophysis reaches the posterior superior iliac spine (Fig. 9) this is seldom seen in the ordinary antero-posterior view of the spine which includes the iliac crests. The explanation is that the posterior superior spine lies much lower in relation to the iliac crest than is usually thought, and cannot be well shown. For this reason it was decided to define the completion of the apophysis as the time at which it dips down to make contact with the iliac crest at its posterior limit, as described also by Risser (Fig. 7).

Of 224 cases there were only six ( 2.6 per cent) in which the apophysis could be seen on one side only. But even in these cases a small ossification centre would almost invariably appear in the naked crest at about the time the opposite apophysis had completed its excursion or fused to the crest.

Whereas a unilateral apophysis is virtually non-existent, asymmetry in their development along the crest was quite frequent. Figure 10 illustrates a typical example of the difference in progress on each side of the pelvis.

In seventy-four cases definite asymmetry in the development of the iliac apophyses was observed. Since the number of cases available for observation of the full evolution of the apophyses was only 102 (Fig. 1) it must be concluded that the incidence of asymmetrical development is high. However, in only twenty-eight out of the seventy-four cases did this asymmetry persist until the time of completion or of fusion of the apophyses to the crest. In forty cases the apophyses had become symmetrical at about the time they had reached the posterior limit of the crest. In six cases the development became asymmetrical only at its last stage, shortly before completion.

In about 15 per cent of the cases in which asymmetrical growth was observed it was noticed that after the one apophysis had made contact with the crest the curvature increased significantly (over 15 degrees). Even in the remaining cases there was usually a slight increase of the curvature while one apophysis was still developing. It seems, therefore, that prognosis as regards deterioration of the curve should depend on the state of maturation of the less advanced apophysis.

Figure 11 shows another interesting feature in the development of the iliac apophyses. An apophysis with a short excursion is illustrated; and sometimes this seems to fuse with the ilium as it grows. There were only eleven cases ( 10 per cent) in this series in which one or both apophyses showed a true short excursion. The incidence is identical with the figure given by Risser (1948). A much higher number (twenty-five cases or 24 per cent) showed a slow development with almost simultaneous fusion to the crest. In some the apophysis at an early stage was growing so near the anterior part of the crest that it could be overlooked, and recorded as absent. Suddenly a year and a half or two years later, even though there was no evidence of it in previous serial films, the " absent" apophysis would be discovered fully grown to the posterior limit and fused!

The incidence of a posterior ossificaton centre was much higher in our series than the 1 per cent reported by Risser (1948). In ninety cases ( 40 per cent) there was radiological evidence of a small or large centre clearly separate from the anterior centre (Fig. 12). The incidence was estimated on the total of our material (224 cases), as the presence of a posterior ossification centre can be identified even at the time of completion of the apophysis. Usually the anterior centre appeared first, but in a few cases the posterior ossification centre was at first the only evidence of the presence of an iliac apophysis. Often the posterior ossification centre will dip down to make contact with the posterior limit of the iliac crest while the main part of the apophysis is still developing along the crest. In view of the high incidence of a posterior ossification centre it was thought worth while to attempt to assess the progress of the curvature from the time of the appearance of this centre in the hope that this might be of prognostic value. The period of study extended from the date when this centre was clearly visible, regardless of whether or not it was in contact with the crest, to the time when the apophysis had either completed its excursion or fused to the crest-in other words up to the 


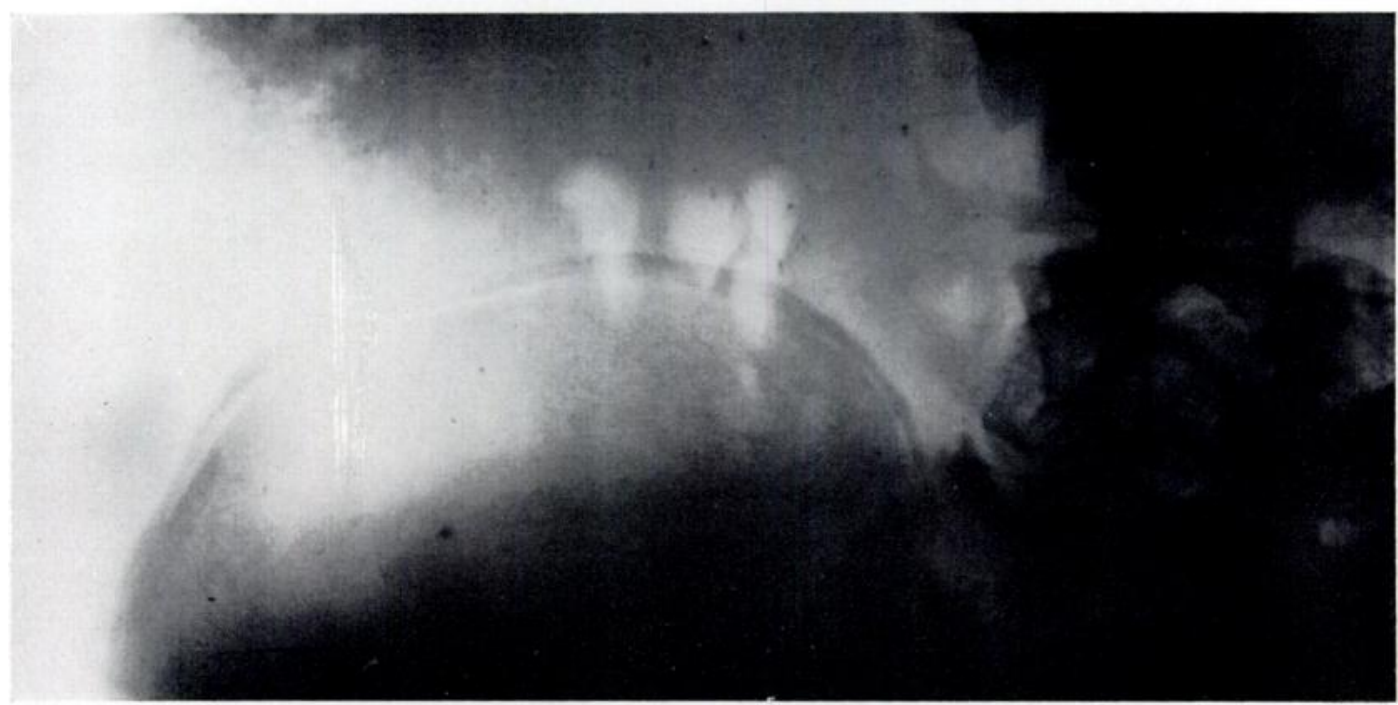

FIG. 9

Shows the apophysis in its complete form reaching the posterior superior iliac spine.

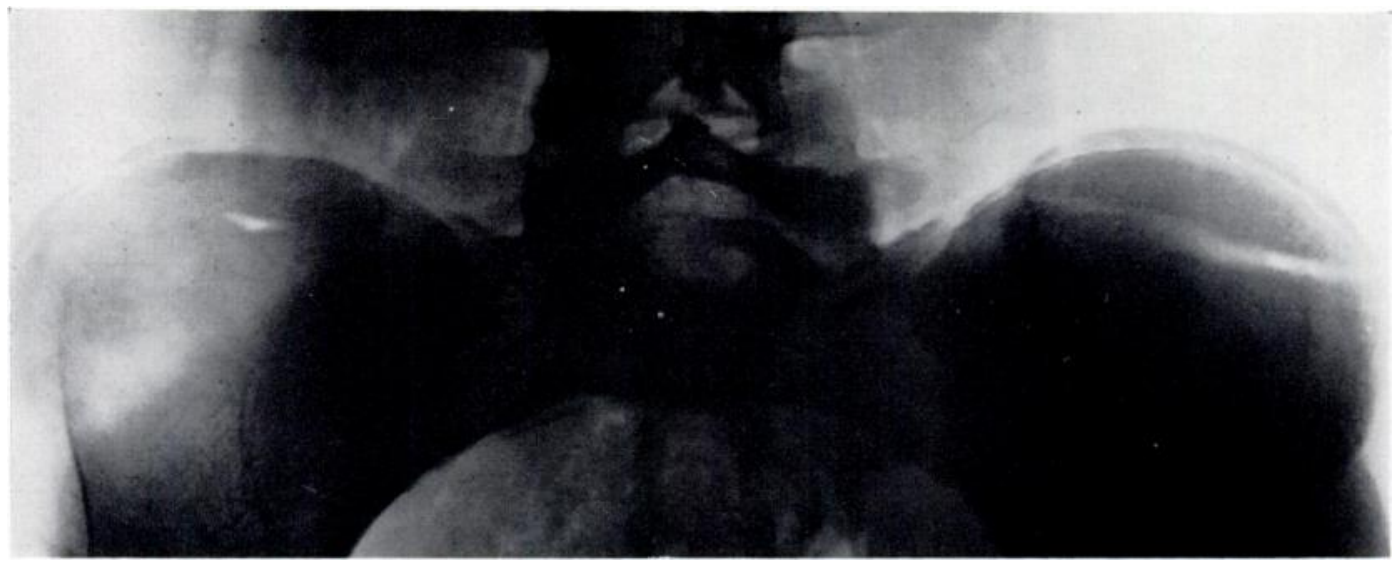

Fig. 10

A typical example of asymmetrical development of iliac apophyses.

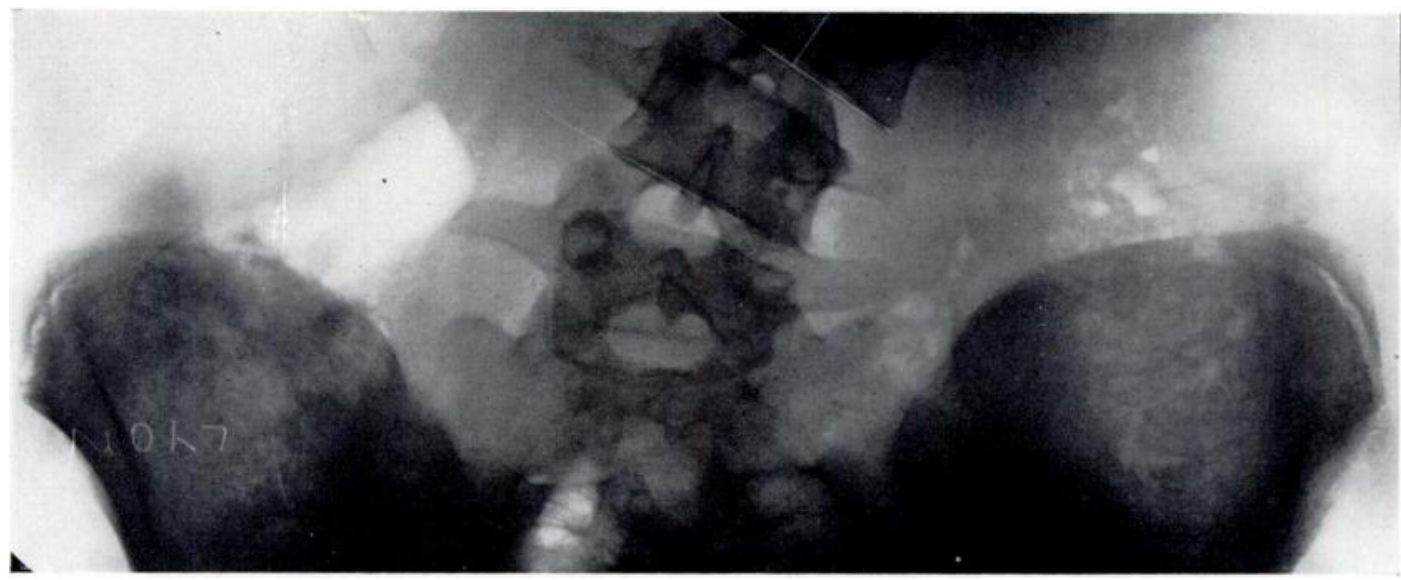

Fig. 11

An apophysis with a short excursion.

VOL. 40 B, NO. 3. ALGUSt 1958 
very end of the apophysial growth. It was found that the average increase of a curvature during this period was no more than 6 degrees, the greatest increase observed being 28 degrees. Only 13 per cent of these cases showed a deterioration of more than 15 degrees, which makes this sign less reliable than the completion of the apophysis ( 6 per cent of cases or 12 patients increased more than 15 degrees (Fig. 1)) but still a valuable observation.

The most unusual anomaly in the development of an apophysis was observed in one case in which a true double excursion could be seen in serial films (Fig. 13).

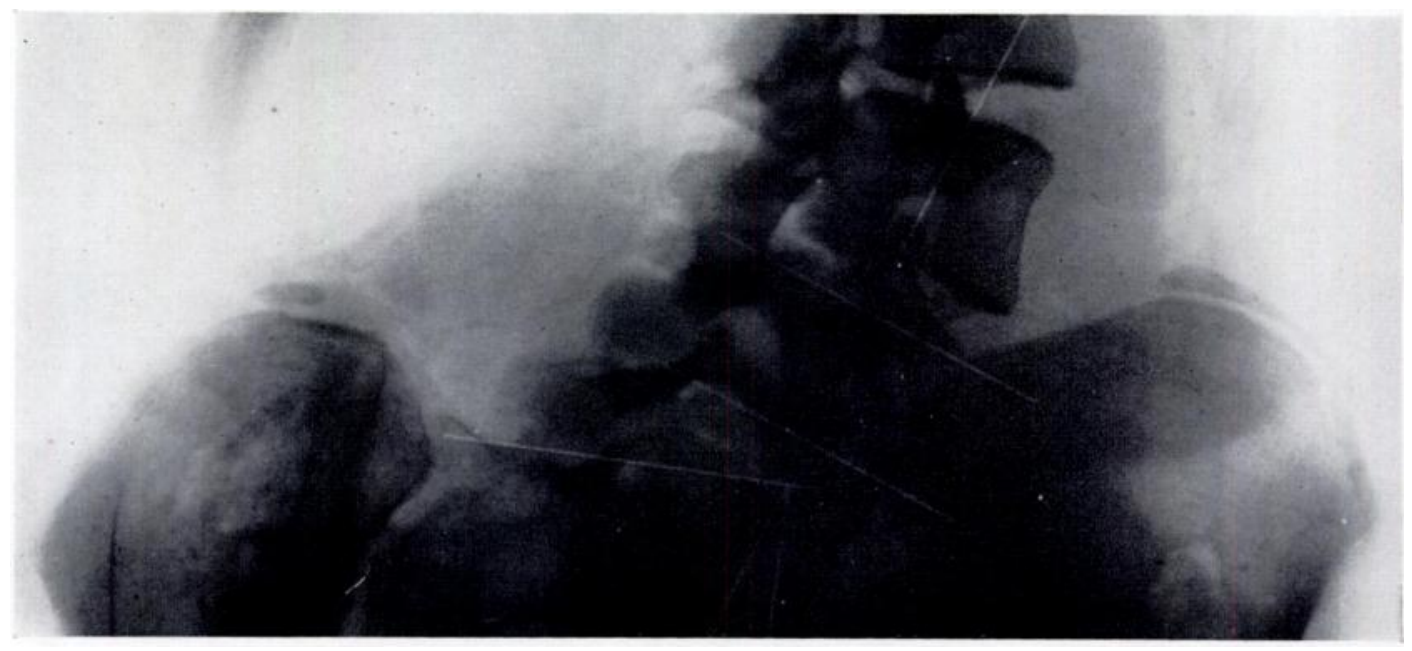

FIG. 12

A posterior ossification centre of the iliac crest, seen on one side.

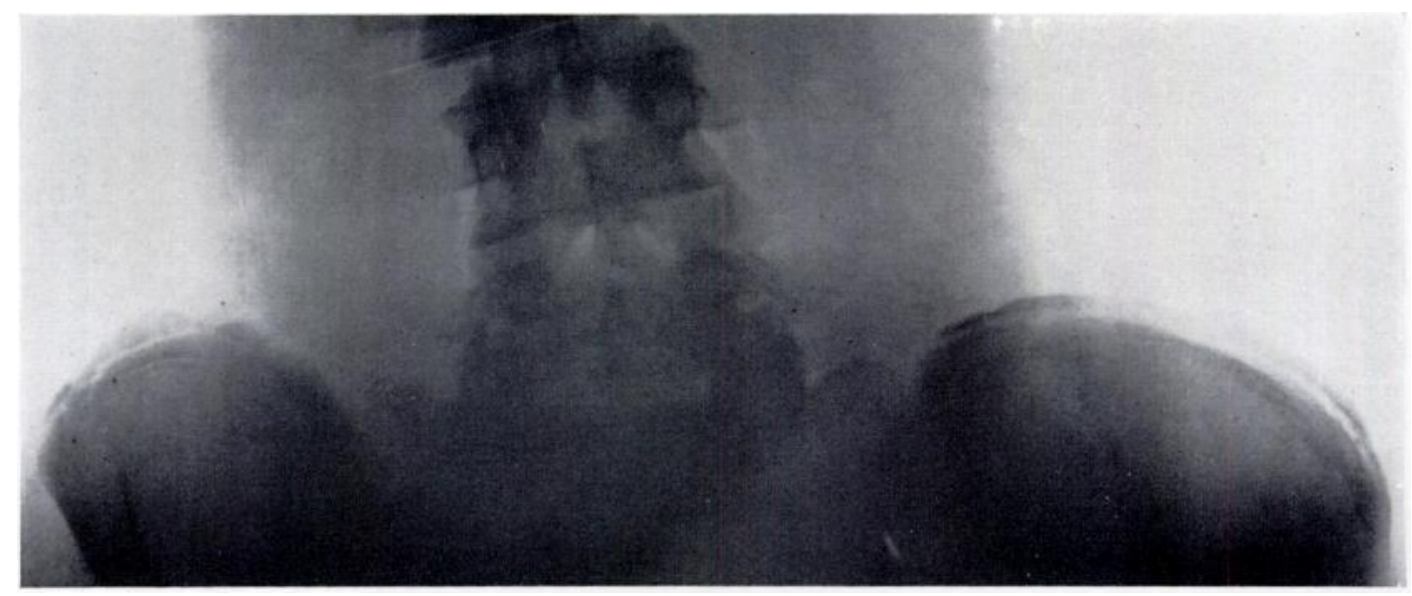

FIG. 13

An apophysis with a double excursion.

\section{CORRELATION OF THE ILIAC APOPHYSIS WITH THE RING APOPHYSIS OF THE VERTEBRAL BODY}

In only a small number of cases was the series of radiographs comprehensive enough to permit a comparative study of the two groups of apophyses. Nevertheless it was possible in 156 cases to obtain at least one lateral view of the spine in which the vertebral apophyses were shown at some stage of their growth, and to compare it with the available films of the iliac apophyses. The views obtained were usually of the thoracic region, and in a number of cases 
there was in addition a view of the lumbar region. The lumbar vertebral apophyses were almost invariably slightly ahead of the thoracic in maturation.

In Figure 14 the combinations of stages of the two types of apophyses as recorded in our series are presented in order of frequency. In only five cases was a truly synchronous evolution of the vertebral ring apophyses and the iliac apophyses seen. In the remaining
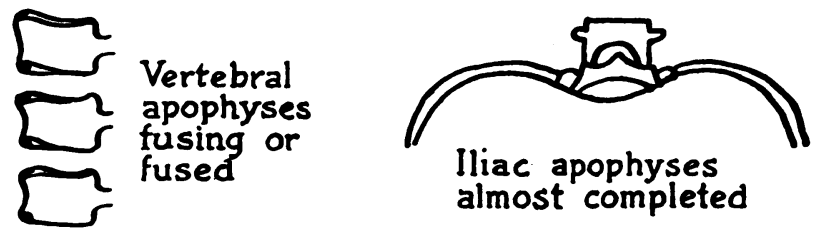

58 patients $(37 \%)$

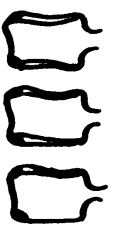

Vertebral apophyses fusing or fused

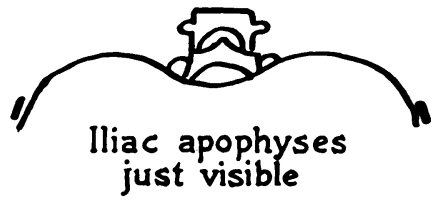

18 patients $(11 \cdot 6 \%)$
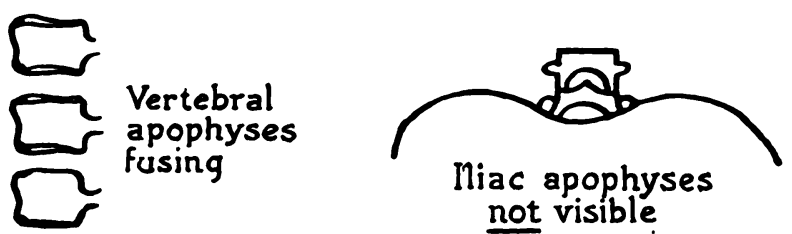

18 patients $(11 \cdot 6 \%)$
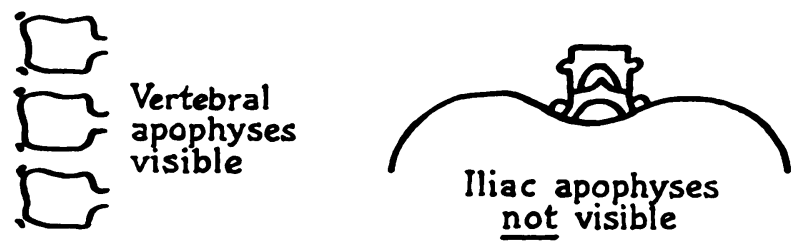

17 patients $(10.8 \%)$
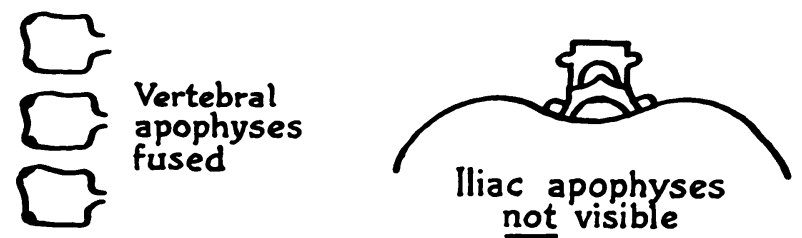

Fig. 14

The growth correlation between vertebral and iliac apophyses. Not included in the diagram were five cases of synchronous development and thirty-seven in which the first radiographs already showed fusion of both.

thirty-seven cases the radiograph available for comparison showed that fusion of both vertebral and ring apophyses had already occurred, but films to demonstrate their earlier development were not available.

The vertebral apophyses appeared at an average age of a little over twelve years, the earliest appearance being observed at the age of nine and a half years and the latest at fifteen and a half years. It was difficult to assess the age at which the apophyses began fusing to the vertebral bodies, because in one and the same film one could, for example, observe the higher thoracic apophyses still clearly separated from the bodies whereas at a lower level the apophyses

vol. 40 B, No. 3, AUGUST 1958 
had begun to fuse. Probably the average age at which fusion began was a little over thirteen years. It was also our impression that, once it had begun, fusion of the ring apophyses with the bodies was such a slow process that the more rapidly growing iliac apophyses ended by completing their fusion almost simultaneously with the vertebral apophyses.

TABLE III

Evolution of Curvatures in Relation to the Growth of the Vertebral Apophyses

\begin{tabular}{|c|c|c|c|}
\hline Period & $\begin{array}{l}\text { Maximum } \\
\text { increase } \\
\text { observed }\end{array}$ & $\begin{array}{l}\text { Average } \\
\text { increase }\end{array}$ & $\begin{array}{c}\text { Percentage } \\
\text { deterioration } \\
\text { over } 15 \text { degrees }\end{array}$ \\
\hline $\begin{array}{l}\text { Period 1-Between appearance of vertebral apophyses and skeletal } \\
\text { maturation (as indicated by fusion of the iliac apophyses): } 31 \text { curves } \\
\text { studied. }\end{array}$ & 54 degrees & 26 degrees & 74 per cent \\
\hline $\begin{array}{l}\text { Period 2-Between the stage of commencing fusion with the } \\
\text { vertebral bodies and skeletal maturation (as indicated by fusion of } \\
\text { the iliac apophyses): } 40 \text { curves studied }\end{array}$ & 54 degrees & 12 degrees & 27 per cent \\
\hline
\end{tabular}

Table III summarises the deteriorations of curvature observed in relation to the growth of the vertebral apophyses. It was thought that two periods were worth study: 1) the period between the appearance of the vertebral apophyses and the termination of skeletal growth as indicated by the completion or fusion of the iliac apophyses; and 2) the period between the time of commencing fusion of the vertebral apophyses and the termination of the iliac apophyses. The group commencing fusion was selected for the study because there is no stage in the evolution of vertebral apophyses comparable to the stage of completion of the iliac apophyses' excursion.

These figures prove that significant deterioration of the scoliotic curve may occur after the appearance of the vertebral ring apophyses or even after they have begun to fuse. It is therefore not so reliable a prognostic feature as the iliac apophysis. Technically it also involves additional lateral radiographs of the spine, whereas the conventional antero-posterior view of the scoliotic curve usually includes the iliac crests.

\section{RELATIONSHIP OF THE ILIAC APOPHYSES TO THE ONSET OF MENSES}

The age of menarche was recorded in practically all of our female patients. The average age was thirteen and a half years, which is a normal figure for this climate and race. This

TABLE IV

Evolution of Curvature After the Onset of Menses

\begin{tabular}{|c|c|c|c|c|c|c|}
\hline \multicolumn{4}{|c|}{ Changes } & \multirow{2}{*}{$\begin{array}{c}\begin{array}{c}\text { From the onset } \\
\text { of menses to } \\
\text { skeletal maturation }\end{array} \\
57 \text { degrees }\end{array}$} & \multirow{2}{*}{$\begin{array}{c}\begin{array}{c}\text { Between appearance } \\
\text { and completion of } \\
\text { iliac apophyses }\end{array} \\
38 \text { degrees }\end{array}$} & \multirow{2}{*}{$\begin{array}{c}\begin{array}{c}\text { After completion } \\
\text { of iliac } \\
\text { apophyses }\end{array} \\
26 \text { degrees }\end{array}$} \\
\hline Maximum increase & . & . & . & & & \\
\hline Average increase & . & . & . & 15 degrees & 13 degrees & 9 degrees \\
\hline \multicolumn{4}{|c|}{ Percentage of deteriorations over 15 degrees } & 41 per cent & 22 per cent & 6 per cent \\
\hline
\end{tabular}

means that menarche was on an average nine months ahead of the appearance of the iliac apophyses and two years ahead of the average time of completion of the apophysial excursion. Unfortunately there were only forty-one cases in the series in which radiographs of the curve were available dating back to the onset of menses. Hence the study of the menstrual history in relation to prognosis of the scoliosis was rather limited in the present investigation. 
In Table IV the worsening of the curve during the period between the onset of menstruation and the termination of skeletal growth (in the sense described previously) are presented. To facilitate comparison, the figures of periods 1 and 2 in the evolution of the iliac apophyses are included in this table.

The high proportion of cases with a significant deterioration after the onset of menstruation tends to support our impression that menarche is not so accurate a prognostic sign as the completion of the iliac apophyses.

\section{SKELETAL AGE AND ILIAC APOPHYSES}

The skeletal age was determined from Greulich and Pyle's Radiographic Atlas of Skeletal Development of the Hand and Wrist in thirty of 224 cases, studied usually because delay in skeletal maturation was suspected.

In nineteen cases the skeletal age was found to be behind the chronological. The discrepancy ranged from several months to as long as three and a half years. (In seven cases chronological and skeletal ages coincided, and in four cases skeletal age was slightly ahead of the chronological.)

It is of interest that in more than half of the nineteen cases in which skeletal growth was retarded the iliac apophyses appeared at or slightly before the normal average age, and furthermore that in fourteen cases the excursion of the iliac apophyses along the crest was completed in the normal average time. This may indicate that even in cases with slow skeletal maturation, as determined at the wrist, the iliac apophysis remains unaffected in its growth.

\section{SUMMARY}

1. The belief that the cessation of spinal growth and curve progression coincides with the completion of growth in the iliac apophyses has been confirmed in a review of material from 224 cases. This applies also to paralytic curves.

2. In a high number of cases this ossification centre showed an asymmetrical development on the two sides of the pelvis. The appearance of a separate posterior centre of ossification is also common, and probably represents an advanced stage in the growth of the iliac apophysis.

3. Menarche and the growth of the apophyses of the vertebral bodies almost always occurred in advance of the iliac apophyses. They should be regarded as early signs of maturation, not reliable in the prognosis of curve progression.

4. The growth of the iliac apophysis appeared to be unaffected by poliomyelitis.

The authors would like to express their thanks to Mrs Glen Haig and the Records Department of the Royal National Orthopaedic Hospital for their kind help in collecting the material, and to Mr R. J. Whitley for the reproduction of the radiographs.

\section{REFERENCES}

Donaldson, W. F. (1957): In Ferguson, A. B., Jun.: Orthopedic Surgery in Infancy and Childhood, p. 159. Baltimore: The Williams \& Wilkins Co.

FLECKER, H. (1942): Time of Appearance and Fusion of Ossification Centers as Observed by Roentgenographic Methods. American Journal of Roentgenology and Radium Therapy, 47, 137.

JAMES, J. I. P. (1954): Idiopathic Scoliosis. Journal of Bone and Joint Surgery, 36-B, 36.

KöHLER, A., and ZIMMER, E. A. (1956): Grenzen des Normalen und Anfänge des Pathologischen im Röntgenbilde des Skelettes. 10e Auflage, p. 435. Stuttgart: Georg Thieme Verlag.

RisSER, J. C. (1948): Important Practical Facts in the Treatment of Scoliosis. American Academy of Orthopaedic Surgeons' Instructional Course Lectures, 5, 248.

SchINZ, H. R. (1922): Altes und Neues zur Beckenossifikation. Fortschritte auf dem Gebiete der Röntgenstrahlen, 30, 66.

Steinder, A. (1950): Nature and Course of Idiopathic Scoliosis. American Academy of Orthopaedic Surgeons' Instructional Course Lectures, 7, 157.

vol. 40 B, No. 3, AUGUST 1958 